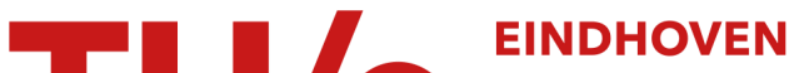 \\ UNIVERSITY OF \\ TECHNOLOGY
}

\section{Classification of reserve capacity in future power systems}

\author{
Citation for published version (APA): \\ Frunt, J., Kling, W. L., \& Myrzik, J. M. A. (2009). Classification of reserve capacity in future power systems. In \\ Proceedings of the 6th International Conference on the European Energy Market (EEM 2009) 27-29 May 2009, \\ Leuven, Belgium (pp. 1275-1/6). Institute of Electrical and Electronics Engineers. \\ https://doi.org/10.1109/EEM.2009.5207144
}

DOI:

10.1109/EEM.2009.5207144

Document status and date:

Published: 01/01/2009

\section{Document Version:}

Publisher's PDF, also known as Version of Record (includes final page, issue and volume numbers)

\section{Please check the document version of this publication:}

-A submitted manuscript is the version of the article upon submission and before peer-review. There can be important differences between the submitted version and the official published version of record. People interested in the research are advised to contact the author for the final version of the publication, or visit the $\mathrm{DOI}$ to the publisher's website.

- The final author version and the galley proof are versions of the publication after peer review.

- The final published version features the final layout of the paper including the volume, issue and page numbers.

Link to publication

\section{General rights}

Copyright and moral rights for the publications made accessible in the public portal are retained by the authors and/or other copyright owners and it is a condition of accessing publications that users recognise and abide by the legal requirements associated with these rights.

- Users may download and print one copy of any publication from the public portal for the purpose of private study or research.

- You may not further distribute the material or use it for any profit-making activity or commercial gain

- You may freely distribute the URL identifying the publication in the public portal.

If the publication is distributed under the terms of Article $25 \mathrm{fa}$ of the Dutch Copyright Act, indicated by the "Taverne" license above, please follow below link for the End User Agreement:

www.tue.nl/taverne

Take down policy

If you believe that this document breaches copyright please contact us at:

openaccess@tue.nl

providing details and we will investigate your claim. 


\title{
Classification of Reserve Capacity in Future Power Systems
}

\author{
J. Frunt, Student Member, IEEE, W.L. Kling, Member, IEEE, J.M.A. Myrzik
}

\begin{abstract}
In electrical power systems must always be a balance between supply and demand. Any imbalance will result in a frequency deviation. To reduce the imbalance to zero, ancillary services for balancing are in use. Ancillary services are characterised by their deployment time and their capacity. By using Discrete Fourier Transform, the kind of ancillary services as well as the requirements for balance management can be characterised in the frequency domain. Agents, that are responsible for maintaining balance in a network, can use the characterisation in the frequency domain to define their needs for reserve capacity. This paper describes a method for spectral analysis of the required reserve capacity. Based on examples and a model, changes in a future power system are discussed using the frequency domain.
\end{abstract}

Index Terms-Ancillary Services, Autonomous Networks, Balancing, Control Power, Electricity Markets, Spectral Analysis.

\section{INTRODUCTION}

$\mathrm{I}_{\mathrm{N}}^{\mathrm{N}}$ $\mathrm{N}$ any electrical power system must always be a balance between supply and demand of electricity. Any imbalance will be compensated in a change in kinetic energy of generators and motors. Therefore any imbalance results in a global frequency deviation from the nominal frequency [1]. To ensure a reliable supply of electricity, frequency deviations must always be within limits. The balance between supply and demand is maintained using reserve capacity. This is capacity that can be started up within a specified time. Usually units with low marginal costs are used for base load production, while units with high marginal costs are used for reserve capacity [2], [3].

To ensure balance of supply and demand, central mechanisms must be incorporated in the system. For instance, the Union for the Coordination of Transmission of Electricity (UCTE) [4] has set up a policy that describes what member states should do in case of a frequency deviation. In this policy different control mechanisms are mentioned that should act in different time frames. Section II of this paper will discuss these control mechanisms.

Due to the large scale implementation of distributed and renewable generation, it is foreseeable that future power

Manuscript received April 21 $1^{\text {th }}$, 2009. This work was supported by the Dutch Ministry of Economic Affairs.

J. Frunt, W.L. Kling and J.M.A. Myrzik are in Eindhoven University of Technology, Eindhoven, 5600MB, the Netherlands (e-mail: j.frunt@tue.nl, w.1.kling@tue.nl, j.m.a.myrzik@tue.nl). systems will have a more complex structure which is less suited for centralised control [5]. It is suggested by several authors that a future power system should be organised in a different way such as based on autonomous networks (ANs) [6], [7]. ANs are aggregations of producers and consumers on both a physical and economic level. An AN is assumed to have perfect behaviour and can be regarded as a single entity from outside. The ANs are capable of trading electricity and must each ensure internal balance. To guarantee this, they should either have balancing capacity themselves or buy this from any other AN [8] in a double sided market. So an AN can decide whether to buy, sell, or produce themselves the ancillary services for balancing.

Based on the requirements or on the ability to supply, different classes for control capacity can be distinguished. Currently these classes are defined by the UCTE as primary, secondary and tertiary control [4]. Each class of control capacity has different characteristics. These characteristics will be further addressed in section III. As each AN is responsible for maintaining its own balance, it should be capable of determining its own needs for reserve capacity per class. Furthermore, in order to trade reserve capacity as a commodity bilarerally or in organised markets, it must be clear what specifications this commodity has. In this paper a technical approach is used to define the commodity of reserve capacity.

To determine the need for control capacity per class, a method based on spectral analysis is discussed in section IV. This concept was first introduced in [9] and will be expanded and illustrated with examples. Based on simulations with a model, changes in the requirements on control power in future power systems will be discussed in section V, using the spectral analysis method. Conclusions of this article are given in section VI.

\section{BALANCING MECHANISMS}

To maintain the balance between supply and demand in the grid, different control mechanisms are in use. For the European synchronous grid, the UCTE has set up a policy for its member states. In this policy, primary, secondary, tertiary and time control are described [4]. This section will elaborate on these different control mechanisms.

\section{A. Primary Control}

Any imbalance between supply and demand of electricity will instantaneously be compensated by a change in kinetic 
energy of rotating generators and motors. This results in a change of frequency. Primary control is designed to stop the change of frequency. A proportional controller will increase power plants' production as the frequency decreases and vice versa. Ideally, the control is evenly distributed over the synchronous grid and locally operational. The amount of primary reserves in the UCTE system is based on a reference incident of $3000 \mathrm{MW}$. This capacity for primary control is fully activated for a disturbance of $+/-200 \mathrm{mHz}$ or more. Deployment is done via a droop function and should be active within 30 seconds after a disturbance as described in [4].

\section{B. Secondary Control}

After primary control has stabilised the frequency, secondary control is activated to bring the frequency back to its nominal value. This should be done in the control zone (country) where the disturbance was caused to avoid unintentional cross-border flows. To enable secondary control, all Transmission System Operators (TSOs) of the control zones measure both cross-border exchange and frequency. They combine these data into an area control error (ACE) which gives information on the balance in the control zone. If an imbalance is detected the TSOs use market mechanisms to deploy control capacity. The goal of secondary control is to drive the ACE to zero using an integral controller. The available control capacity for secondary control is based on the maximum load in a year in each control zone. In total this comes to an amount of approximately $5700 \mathrm{MW}$ for the UCTE synchronous grid. Secondary control should be capable of being deployed within 900 seconds after a disturbance.

After a disturbance, first primary control is activated to stabilise the frequency. Afterwards secondary control restores the frequency to its nominal value. The relative individual actions of the control mechanisms are displayed in Fig. 2 whereas the frequency is shown in Fig. 1.

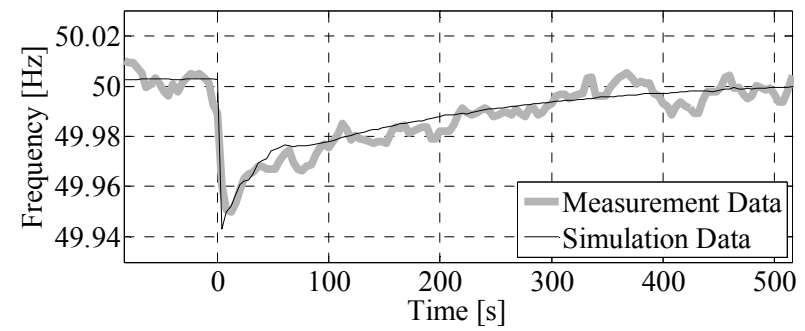

Fig. 1. Frequency during a disturbance.

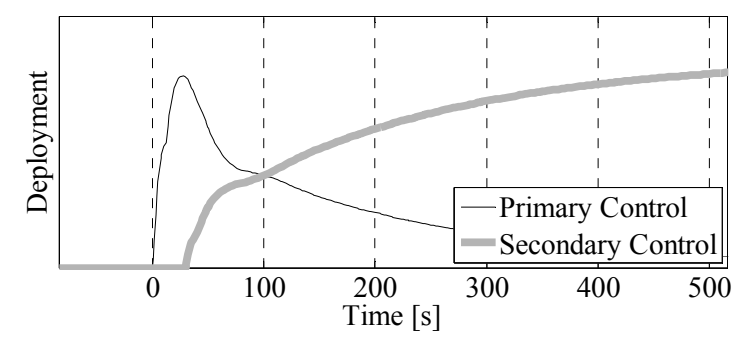

Fig. 2. Primary and secondary control action during a disturbance.

\section{Tertiary Control and Time Control}

Tertiary control used to be the mechanism to free secondary reserves after deployment and to economically optimise the deployment of reserve capacity. However, since the liberalisation of the electricity sector, economic dispatch is no longer a task of the TSOs but is market based.

Time control is the control that makes the average frequency equal to the nominal frequency of $50 \mathrm{~Hz}$. If the average frequency deviation exceeds a threshold the frequency set point in the complete synchronous zone is set to either 49.99 $\mathrm{Hz}$ or to $50.01 \mathrm{~Hz}$ for full periods of one day.

\section{RESERVE CHARACTERISTICS}

As described in the previous section, the two control mechanisms deploy two classes of control capacity. The capacity available in these classes is defined by different rules. For the existing primary and secondary reserves, the main characteristics are given in the following Table I.

TABLE I

CHARACTERISTICS OF RESERVE CAPACITY

\begin{tabular}{|c|c|c|}
\hline & & \\
\hline $\begin{array}{l}\text { Deployment time } \\
\text { UCTE canacitv }\end{array}$ & 30 seconds & 15 minutes \\
\hline UCTE capacity & $3000 \mathrm{MW}$ & $5700 \mathrm{MW}$ \\
\hline Ramping rate & $200 \% / \mathrm{min}$ & $7 \% / \mathrm{min}$ \\
\hline Activation duration & $<15$ min & Not specified \\
\hline
\end{tabular}

Due to the implementation of distributed generation both the needs and the availability of control capacity may change. As each class of control capacity has a specific power, rise time, and, in case of energy limited generation, maximum energy and recovery time, it was suggested in [9] to characterise reserve capacity in the frequency domain. Both the demand for control capacity as well as the supply can be specified. In power systems based on ANs, each AN should be able to identify its own needs and availability of control capacity. In this way, supply and demand for control capacity can be matched. Characterisation of control capacity is also required to enable trade in this commodity [10].

Contrary to existing methods for analysing the needs for reserve capacity, characterisation of the availability of control power in the frequency domain enables a discussion on the reserve capacity classes to optimally match supply and demand. Furthermore, it provides quantitative results for new concepts or means like e.g. storage devices, in balancing systems.

\section{Spectral ANALysis of ReSERVE CAPACITy}

In future power systems, each AN could analyse its needs for control power and thus make bids for either buying or selling this commodity bilaterally or in an organised market. To evaluate both the demand and for the supply of reserve capacity, spectral analyses can be performed. This section explains the methodology for this spectral analysis.

\section{A. Method for spectral analysis}

Assume that any load's or generator's profile is given as a function of time $y(t)$. To transform this signal into the frequency domain, Fourier transformation can be used. As in practice $y(t)$ often consists of discrete-time measurement data, 
Discrete Fourier Transform (DFT) can be applied. Assume a continuous-time signal $f(t)$ sampled each $\tau$ seconds over a time span of $\mathrm{N} \tau$ in $\mathrm{N}$ samples. The sample number $\mathrm{k}$ is defined as $\mathrm{k}=0,1,2 \ldots \mathrm{N}-1$. Therefore $\mathrm{f}_{\mathrm{k}}=\mathrm{f}(\mathrm{k} \tau)$. The DFT is defined as (1):

$Y(n)=\sum_{k=0}^{N-1} f_{k} \cdot e^{\frac{2 \cdot \pi j \cdot n \cdot k}{N}}$

This gives $\mathrm{N}$ Fourier components for each $\mathrm{n}=0,1 \ldots \mathrm{N}-1$ whereas the relation between $\mathrm{n}$ and the angular frequency $\omega$ of a time continuous signal is given $\omega=2 \pi \mathrm{n} /(\mathrm{N} \tau)$ [11].

Parsevals' theorem states that the energy of a signal is equal to the sum of the energy density of its Fourier components [11]. Therefore it can be stated that the energy content of the signal in the frequency band $\left[\omega_{1}, \omega_{2}\right]$ can be found with (2):

$E\left(\omega_{1}, \omega_{2}\right)=\sum_{\omega_{1}}^{\omega_{2}}|Y(\omega)|^{2}$

As the classes of control power are defined by specific frequency bounds $\omega_{1}$ and $\omega_{2}$ the energy content of each class is equal to $E\left(\omega_{1}, \omega_{2}\right)$. To find the corresponding capacity (3) can be used. Note that by using (2) and (3) any phase angle information in $\mathrm{Y}(\omega)$ is lost.

$P\left(\omega_{1}, \omega_{2}\right)=\sqrt{\sum_{\omega_{1}}^{\omega_{2}}|Y(\omega)|^{2}}$

To illustrate the method, the next sections will give examples based on generation and consumption data.

\section{B. System Load Analysis}

Assume that the difference between the predicted load and the read load of a control zone needs to be compensated by reserve capacity. To identify the specific needs for control capacity, the spectral analysis method can be used. As input data, 4 second load values from a week in December 2008 from the Dutch TSO (TenneT TSO b.v.) are taken. Since only variations from the predictable load signal are of interest, low frequencies until $1 /(60 \cdot 60 \cdot 5) \mathrm{Hz}$ (period of 5 hours) are removed using a high pass filter. The measured, predicted and filtered load signals are displayed in Fig. 3.

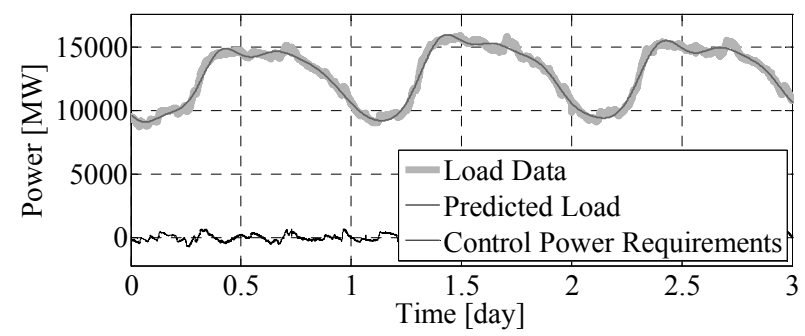

Fig. 3. System load data, predicted load and control power requirements signals for further analysis.

This signal is transformed into the frequency domain using Fast Fourier Transform after applying a Hanning window with a correction factor of two to remove discontinuities [11]. The resulting frequency spectrum is given in Fig. 4. A peak at frequency $=0 \mathrm{~Hz}$ would mean a constant deviation from the predicted load.

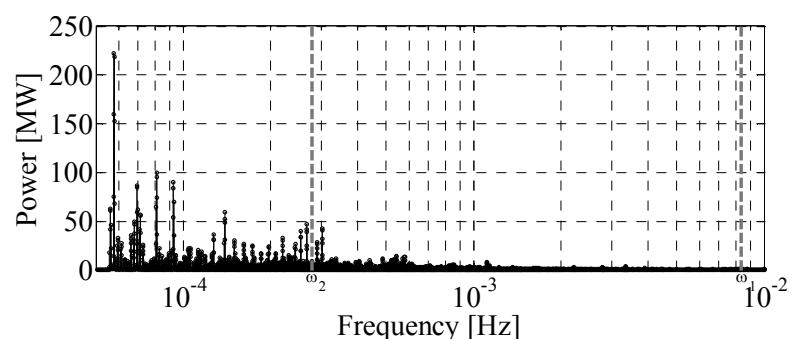

Fig. 4. Spectrum of the system load control power requirements for Dec 2008.

As classification groups, the existing (i.e. primary and secondary) control classes are used. These have a rise time of 30 and 900 seconds respectively. Taking into account that the rise time takes one quarter of the period in a sinusoidal signal, the class boundaries $\omega_{1}$ and $\omega_{2}$ are the angular frequencies corresponding to periods of 120 and 3600 seconds respectively. With this, three different classes are identified:

1) Class 1 , slow reserves ( $>15$ minutes): frequencies from 0 to $1 / 3600 \mathrm{~Hz}$;

2) Class 2, middle reserves $(>30$ seconds and $<15$ minutes): frequencies from $1 / 3600$ to $1 / 120 \mathrm{~Hz}$;

3) Class 3 , fast reserves $(<30$ seconds): frequencies from $1 / 120 \mathrm{~Hz}$ to infinity.

The capacity for each class is found by filling out the boundary values for $\omega_{1}$ and $\omega_{2}$ in (3). Fig. 5 shows that mainly slower reserves (classes 1 and 2) are required for variations from the expected load value.

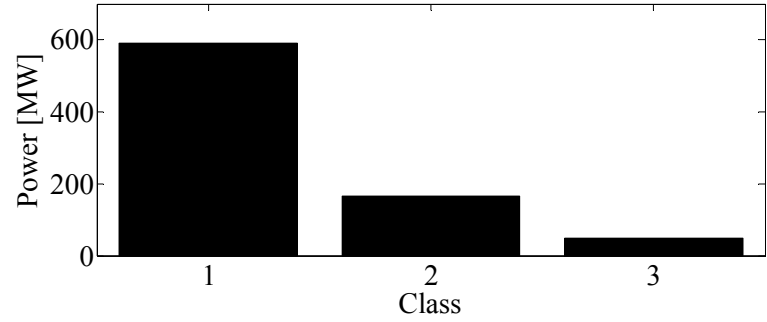

Fig. 5. Classification of reserve capacity for system load variations.

\section{Industrial Load Analysis}

Assume an AN that consists only of an industrial facility. This facility has a load which is created with a normally distributed random function (average $\mu=100 \quad \mathrm{MW}$ and standard deviation $\sigma=60 \mathrm{MW}$ ) and a low pass filter (Fig. 6).

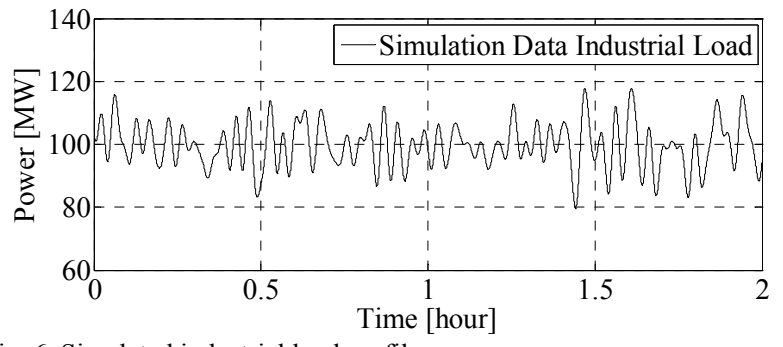

Fig. 6. Simulated industrial load profile.

After the random data are generated with a sampling time of 1 second, a low pass filter with a cut-off frequency of $1 /(60 \cdot 2)$ $\mathrm{Hz}$ (period of 2 minutes) is applied to increase autocorrelation of the dataset. If the method from section IV A is applied to this data it can be seen that this AN should have a 
considerable amount of reserve capacity available in different classes to compensate the deviations from a constant load of 100 MW. This is illustrated in Fig. 7.

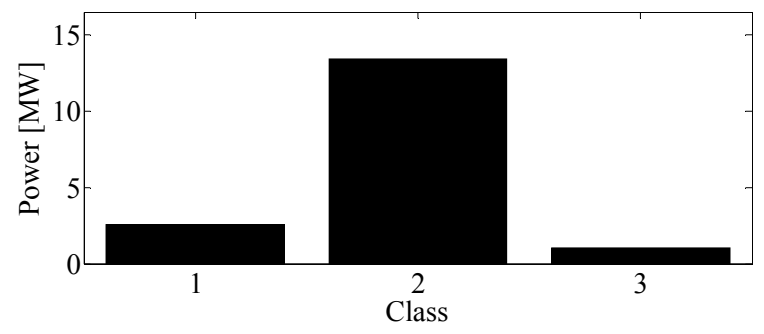

Fig. 7. Classification for reserve capacity for industrial load profile.

\section{Wind Power}

Wind power is implemented more and more in the power system. Wind power production however can be fluctuating with limited predictability. An AN with wind turbines will need to have control capacity available if it wants to achieve a balance or constant power output. The need for these reserves can be investigated with the spectral analysis method. For a group of 17 identical $1.5 \mathrm{MW}$ wind turbines with a combined nominal capacity of $25.5 \mathrm{MW}, 1$ second output data are generated by the linear interpolation of data with a sampling interval of 1 minute. The required control capacity is the difference between the actual power output and a fixed value. In this case the median of the wind production is used as a fixed value for desired total production. The need for control capacity in the different classes is illustrated in Fig. 8.

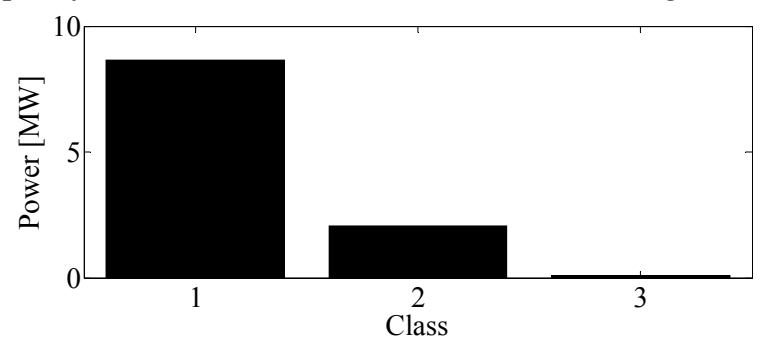

Fig. 8. Control capacity requirements for a group of wind turbines. For this figure the combined power output of 17 identical $1.5 \mathrm{MW}$ turbines of the Slufter wind farm in the Netherlands was used.

\section{E. Electricity Storage}

Often, electricity storage is mentioned as the enabling factor for further integration of renewable, distributed generation. The storage capability can mitigate fluctuations in renewable power production thus making it more reliable and attractive for utilities. However, in the existing regulatory frameworks for reserves, storage can make no bids in the imbalance system (or imbalance market) because of energy constraints. Characterisation of reserve capacity using the frequency domain would however include both on-time and off-time. Both the discharging and the charging process of the storage can be taken into account.

The time that a storage device can supply reserve capacity depends both on the technical specifications of the storage device and on the strategy of its owner. If storage is deployed as fast control power, it can supply high power during a short period. However, if it is deployed as slow control capacity it will only provide smaller amounts of control capacity. This is illustrated in Fig. 9.

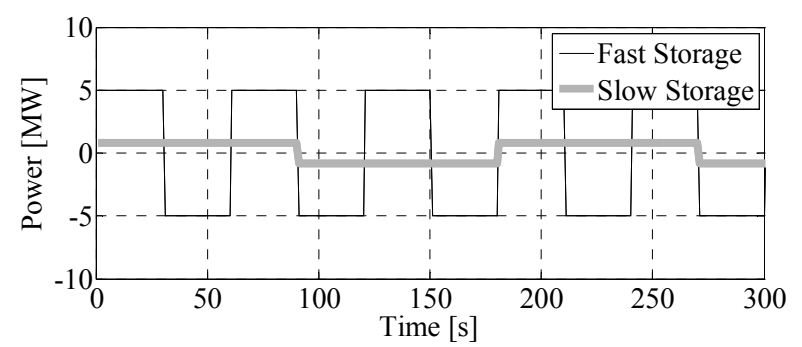

Fig. 9. Charging and discharging processes of fast and slow storage.

Both strategies can be compared in the frequency domain. An example is given for two storage devices. For both types of storage the energy contents are identical. The fast storage has a discharging time of 30 seconds while the slow storage has a discharging time of 90 seconds. The spectral analysis of supply of reserve capacity is given in Fig. 10.

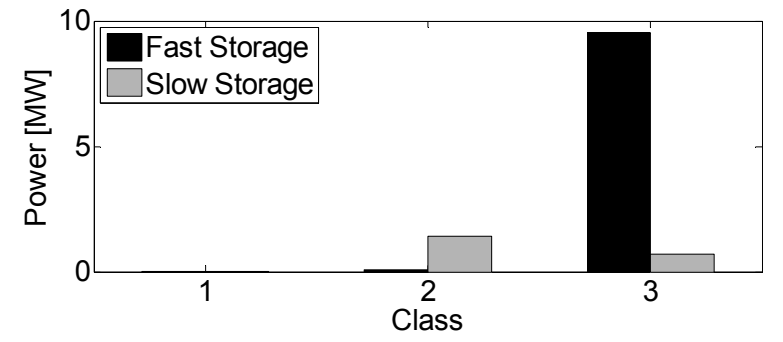

Fig. 10. Spectral analysis of fast and slow storage capacity.

As can be concluded, the deployment strategy of storage determines its functionality. The spectral analysis method can be used to identify what types of electricity storage and which strategy is required for a specific demand for reserve capacity.

\section{MODEL}

Future power systems are considered to have different characteristics compared to current power systems. Therefore, this section will explain how changes in the power system will influence the need for control capacity. This is investigated with a model based on [1], [12] and [13] combined with the methodology based on spectral analysis, which was explained in section IV.

\section{A. Changes in the Power System}

As stated before, the future power system will have different characteristics. This section addresses the following cases:

1) Reduced inertia; due to the replacement of synchronous generators that have inertia, by generators based on power electronics, the inertia of the grid will reduce. As the inertia damps frequency changes in case of a disturbance, larger deviations are expected.

2) Increased amounts of distributed generation; an increase of distributed generation will lead to larger uncertainties in the production side. This will cause more imbalances between supply and demand.

3) Use of Demand Side Management (DSM); discrepancies between supply and demand are (partially) removed using the price sensitivity of consumers. 


\section{B. Model Implementation}

The changes mentioned above are implemented in a model of a power system. This model consists of generation, primary and secondary control, load and inertia. A single control zone is modelled as being part of a larger synchronous grid. The set-up of the model is illustrated in Fig. 11.

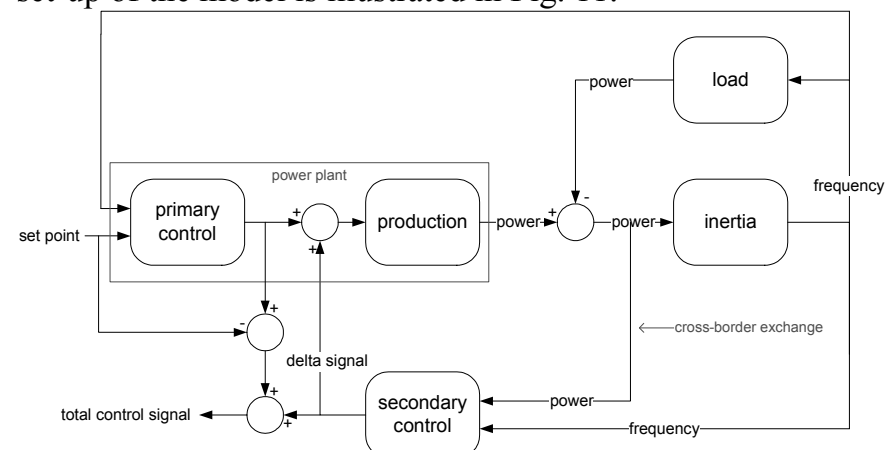

Fig. 11. Power system model with production, load, inertia, primary and secondary control [13]. The output of the model is the total control signal.

Output of the model is the combined primary and secondary control action in the system which can be analysed with the spectral analysis methodology. In the base case $\left(\mathrm{C}_{0}\right)$ a 1500 MW disturbance takes place at $t=0 \mathrm{sec}$. This leads to an imbalance and a frequency deviation that are reduced to zero using primary and secondary control (Fig. 1 and Fig. 2). The three changes in the power system are implemented as follows:

1) To simulate a reduction of the inertia of the system (further $\mathrm{C}_{1}$ ), the inertia constant in the grid is reduced from $30.000 \mathrm{MW} / \mathrm{Hz}$ to $10.000 \mathrm{MW} / \mathrm{Hz}$.

2) To simulate production by dispersed generation, the generation block is adjusted. In the base case, production follows the load and the complete production is influenced by primary and secondary control. In this case $\left(\mathrm{C}_{2}\right)$ part of the production is replaced by wind generation. The wind generation is modelled by using measurement data from a single wind farm, which cannot be controlled by primary and secondary control.

3) In the base case the self-regulating effect of the load is set to $1 \% / \mathrm{Hz}$. This means that if the frequency drops by 1 $\mathrm{Hz}$, the total load will be reduced by $1 \%$ [8]. In DSM it is assumed that electricity consumption can be controlled by price. In this case it is assumed that there will be an increasing share of frequency responsive load. To simulate this DSM (further $\mathrm{C}_{3}$ ), the self-regulating effect of the load is increased.

For the base case plus the three other cases, simulations are run. The total requirements for control capacity, being the sum of primary and secondary control, are marked as 'total control signal' in Fig. 11. It is assumed that requirements for control power, i.e. droop for primary control and variables for the PIcontrol in secondary control, are constant in all cases. The total control action is stored and the spectral analysis method, which was explained in section IV, is applied. The same class definitions from section IV are used for the model. The results are discussed next.

\section{Model Results}

The three changes in the power system all influence the need for control power in a different way. The fault which is simulated at $t=0$ results in different frequency responses which are shown in Fig. 12.

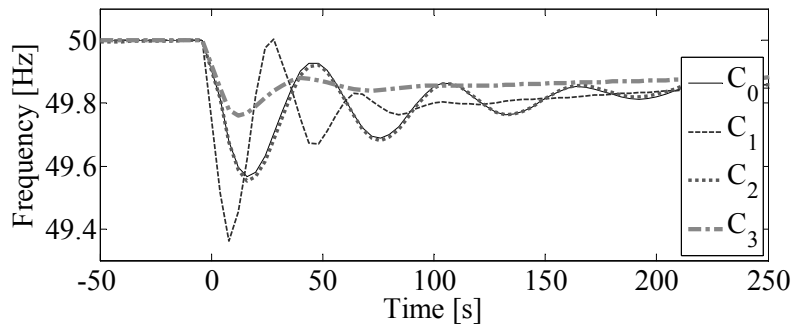

Fig. 12. Frequency response for a $1500 \mathrm{MW}$ disturbance for the different cases. The different cases correspond to possible future changes in the power system compared to a base case $\left(\mathrm{C}_{0}\right)$.

Using the spectral analysis method, the requirements for control capacity are analysed for the different cases. Fig. 13 shows the requirements for control capacity in the different classes.

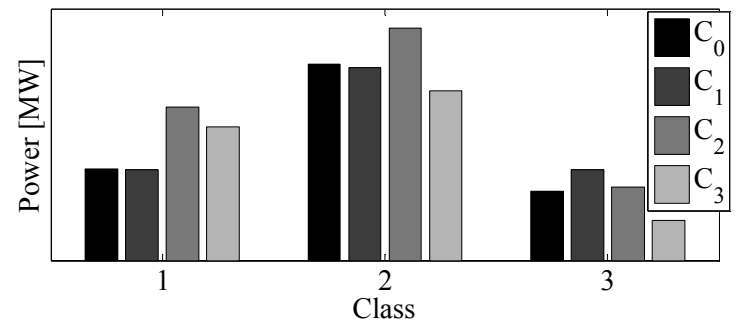

Fig. 13. Control capacity requirements for the different cases (base $\left(\mathrm{C}_{0}\right)$, lower inertia $\left(\mathrm{C}_{1}\right)$, wind power $\left(\mathrm{C}_{2}\right)$ and DSM $\left.\left(\mathrm{C}_{3}\right)\right)$ and different classes.

The three cases $\left(\mathrm{C}_{1}, \mathrm{C}_{2}\right.$ and $\left.\mathrm{C}_{3}\right)$ can be compared to the base case $\left(\mathrm{C}_{0}\right)$.

1) If the inertia of the grid is reduced, larger frequency deviations will occur. Since primary control is activated proportionally with the frequency deviation, a reduction of inertia will require more primary control. This can be seen in Fig. 13 as the fast class (3) of control capacity is activated more. The other classes of control capacity are not influenced by a change of inertia.

2) The stochastic nature of distributed generation which can neither participate in primary control nor in secondary control results in different requirements for control capacity. Changes in wind power production do not affect the needs for very fast control capacity. However, the slower classes 1 and 2 are used more because of the fluctuations in wind power.

3) DSM is assumed to work instantaneously and is integrated in the model by changing the frequency response of the load. It can be concluded that this results in a reduction of requirements of the 2 fastest classes of control capacity. The rate of change in requirements depends on the implementation of DSM. As a disturbance takes place, the frequency decreases. Because of the frequency dependency, the load will decrease and thus mitigate the frequency deviation. This causes a decrease 
in the need for fast control capacity (class 3 ). However, as the frequency is being restored, load will increase again thus requiring more capacity. This explains the increase in need for slower control capacity in class 1.

\section{CONCLUSIONS}

To continuously match supply and demand in power systems, control capacity is kept available. Different classes of control capacity have been defined based on requirements and generation specifications. Currently these different classes are addressed as primary, secondary, tertiary and time control.

Due to the implementation of decentralised generators in the grid, future power systems are assumed to be more complex. One of the structures to deal with this increased complexity is based on ANs. Each AN will be responsible for maintaining its own internal balance between the supply and demand of electricity. To analyse ANs' need for, and ability to supply control capacity this paper discussed a method, based on spectral analysis, to identify the required or available control capacity per class. This method has been demonstrated for different loads and generators. Currently, the energy constraints and recovery time of generators are not taken into account in the characterisation of control capacity. As a result, storage for example, cannot make lucrative bids as control capacity in a reserve market. However, characterisation with the proposed method in the frequency domain would enable storage to provide ancillary services for balance management by changing some of the restrictions in the current bidding system.

Due to the integration of renewable generation and the implementation of DSM, future power systems will have different characteristics than current power systems. By using a model of a power system, the paper qualitatively discusses the influence of these changes on the requirements of control capacity. For this article the existing classes (primary and secondary control) have been used. The integration of other types of generation could however require a change in this classification. The spectral analysis method, discussed in this paper, can be used to optimise this classification by changing the number of classes and the class boundaries to better match supply and demand requirements of reserve capacity.

\section{ACKNOWLEDGEMENTS}

This article is part of the project RegelDuurzaam, which is an EOS-project (Energy Research Subsidy Project) funded by the Dutch Ministry of Economic Affairs. The authors acknowledge grid operator Stedin B.V. for the provision of the power measurement data of the Slufter wind farm.

\section{REFERENCES}

[1] P. Kundur, Power System Stability and Control, McGraw-Hill Inc., 1994, pp. 581-626.

[2] S. Stoft, Power System Economics - Designing Markets for Electricity, Wiley-IEEE Press, 2002.

[3] F. I. Denny, and D. E. Dismukes, Power System Operations and Electricity Markets, vol. I. Boca Raton: CRC Press, 2002, chapter 9.

[4] UCTE, "Operation Handbook, Policy 1: Load-Frequency Control and Performance," Union for the Co-ordination of Transmission of
Electricity, Tech. Rep., 2004. [Online]. Available: http://www.ucte.org/_library/ohb/policy1_v22.pdf.

[5] P. H. Nguyen, and W. L. Kling, and J. M. A. Myrzik, "Promising concepts and technologies for future power delivery systems," in $42^{\text {nd }}$ International Universities Power Engineering Conference, Brighton, United Kingdom, 2007.

[6] F. Provoost, and A. Ishchenko, and A. Jokic, and J. M. A. Myrzik, and W. L. Kling, "Self controlling autonomous operating power networks," in CIRED $18^{\text {th }}$ International Conference on Electricity Distribution, Turin, Italy, 2005

[7] A. Jokic, "Price-based optimal control of electrical power systems," Ph.D. dissertation, Dept. Elec. Eng., Eindhoven Univ. of Technology, 2007.

[8] J. Frunt, and A. Jokic, and W. L. Kling, and J. M. A. Myrzik, and P. P. J. van den Bosch, "Provision of ancillary services for balance management in autonomous networks," $5^{\text {th }}$ International Conference on European Electricity Market 2008, Lisbon, Portugal, 2008.

[9] F. L. Alvarado, "Spectral analysis of energy-constrained reserves," Proc. of the 35th Hawaii international conference on system sciences 2002, pp. 749-756, Jan. 2002.

[10] J. R. Arce, and M. D. Ilić, and F. F. Garcés, "Managing short-term reliability related risks," IEEE Power Engineering Society Summer Meeting 2001, vol.1, pp. 516-522, 2001.

[11] M. Cartwright, Fourier Methods for Mathematicians, Scientists and Engineers, Ellis Horwood Limited, 1990, pp. 77-220.

[12] B. Roffel, and W. W. de Boer, "Analysis of power and frequency control requirements in view of increased decentralised production and market liberalization," Control Engineering Practice, vol. 11, no. 4, pp. 367375, Apr. 2003.

[13] B. C. Ummels, and M. Gibescu, and W. L. Kling, and G. C. Paap, "Development of a simulation model for secondary control performance assessment with significant wind power in a market environment," in $16^{\text {th }}$ Power Systems Computations Conference, Glasgow, Scotland, 2008.

\section{BIOGRAPHIES}

Jasper Frunt was born in 's-Hertogenbosch in 1981. He received his B. degree in electrical engineering in 2003 from the University of Professional Education in 's-Hertogenbosch. In 2006 he received his M.Sc. degree in sustainable energy technology from Eindhoven University of Technology. For his graduation projects he worked with Kema N.V. and Tennet TSO bv (Dutch Transmission System Operator) respectively. Currently he is a PhD in the EOS (Energy Research Subsidy) project 'Regelduurzaam' for Eindhoven University of Technology. His research focuses on current and future deployment, legislation and organisation of control power for balance management.

Wil L. Kling received his M.Sc. degree in electrical engineering from the Technical University of Eindhoven in 1978. Since 1993 he has been a (parttime) professor in the Department of Electrical Engineering at Delft University of Technology, in the field of Power Systems Engineering. Since 2008, he is a full-time professor at Eindhoven University of Technology where he is leading research programs on distributed generation, integration of wind power, network concepts and reliability. Prof. Kling is involved in scientific organisations such as CIGRE and the IEEE. As Netherlands' representative, he is a member of CIGRE Study Committee C6 Distribution Systems and Dispersed Generation, and the Administrative Council of CIGRE.

Johanna M. A. Myrzik was born in Darmstadt, Germany in 1966. She received her MSc. in Electrical Engineering from the Darmstadt University of Technology, Germany in 1992. From 1993 to 1995 she worked as a researcher at the Institute for Solar Energy Supply Technology (ISET e.V.) in Kassel, Germany. In 1995 Johanna joined to the Kassel University, where she finished her $\mathrm{PhD}$ thesis in the field of solar inverter topologies in 2000. Since 2000, Johanna is with the Eindhoven University of Technology. In 2002 she became an assistant professor and since 2008 she is an associate professor in the field of residential electrical infrastructure and distributed generation. Her fields of interests are: power electronics, renewable energy, distributed generation, electrical power supply. 